\title{
General Psychiatry New journey, new mission: bolstering international communication about mental health
}

\author{
Yifeng Xu
}

To cite: Xu Y. New journey, new mission: bolstering international communication about mental health. General Psychiatry 2018;31:e100002. doi:10.1136/ gpsych-2018-100002

Received 10 August 2018 Accepted 13 August 2018

Check for updates

(C) Author(s) (or their employer(s)) 2018. Re-use permitted under CC BY-NC. No commercial re-use. See rights and permissions. Published by BMJ.

Shanghai Mental Health Center, Shanghai Jiao Tong University, School of Medicine, Shanghai, China

Correspondence to

Yifeng Xu;

xuyifeng@smhc.org.cn
In the wake of the rapid economy and society development, phenomena such as industrialisation, urbanisation, marketisation and the ageing of the population have shown an accelerating trend. As a result, mental health issues due to these phenomena are increasingly serious, making mental health both concerning public health and societal issues that have a great impact on economic and social development. ${ }^{1}$ In 2014, there were 16 million persons with severe mental disorders in China. The prevalence of all mental diseases reached $13.47 \%$, ranking number one in the overall burden of disease and accounting for $20 \%$ of the overall burden of disease. By the year 2020, the ratio of mental illness to the overall burden of disease was projected to rise to $25 \%$. $^{2}$ Unfortunately, the mental health service resources and professional capability that China currently possesses are far from enough. Furthermore, the acquisition of information and knowledge pertaining to mental health development domestically and abroad does not come easily to physicians. A tremendous number of psychiatric patients do not receive timely and effective treatment and rehabilitation. Consequently, it affects the quality of life of patients and their family, and brings a heavy burden to society. Therefore, effective dissemination and communication of the concepts and research progress in psychiatry domestically and internationally are of extraordinary significance.

As the first psychiatric academic journal in Mainland China, General Psychiatry (formerly known as Shanghai Archives of Psychiatry) has all the while been devoted to the elimination of the mental health knowledge gap, publication of strong academic clinically focused scientific literature, and serving the national psychiatry field and the general public. Since the transition to publication in English (bimonthly) in 2012, the journal has become the only English psychiatry journal published in Mainland China. The publisher Shanghai Mental Health
Center, as the largest mental health institution in China, has a leading position in the field of psychiatry. Since August 2018, the Shanghai Archives of Psychiatry has changed its name to General Psychiatry and joined the journal portfolio of the BMJ Publishing Group, which is one of the most influential medical publishers in the world. The aim is to meet the development and needs of psychiatric research, better develop our research platform, gain a broader international scope and acquire a better position in the field of global psychiatry.

Since the first issue in 1959, Shanghai Archives of Psychiatry has been insisting on publishing highly academic, high-quality and clinical scientific literature to serve the Chinese psychiatry field and the social public. After 60 years of constructing our academic research platform, General Psychiatry has laid a considerable foundation for ascending to an international journal. The constitution of the editorial board adequately reflects the depth, scope and diversity of our journal. We are more than grateful for the participation of our editorial board which includes many internationally renowned psychiatrists and particularly the Editors-in-Chief of the Archives of Psychiatry, the American Journal of Psychiatry and the British Journal of Psychiatry. This will help expand the source of international manuscripts and attract high-quality manuscripts. The potent international editorial board, competent editorial department and complete office facilities provide the journal with sustainable academic and technical support. Under the perseverance and effort of our senior experts and the former and current editorial staff, the journal has been indexed by many influential databases, namely PubMed Central, Scopus, ProQuest, PsycINFO, EBSCO, Google Scholar, Directory of Open Access Journals, Academic OneFile, Advanced Placement Psychology Collection, Health Resource Center, Chemical 
Abstracts, and Chinese Science Citation Database core journals.

As a global open access journal, General Psychiatry is dedicated to the continuous publication of cutting-edge research in areas including clinical and basic researches of psychiatry, brain science, and public mental health, which readers can enjoy free access for the reason of the heavy emphasis on our readers' support and attention given to the journal. The main sections included in our journal are Original Articles, Meta-analysis/Systematic Review, Forum, Commentaries, Case Reports and a featured 'Biostatistics in Psychiatry' section.

General Psychiatry is like a mountain climber, constantly scaling higher and higher while showing the mystery of psychiatry to the world. Each reform is bound to face many challenges, and each success is reached after overcoming countless difficulties. In the midst of increasingly fierce competition among psychiatry journals, General Psychiatry keeps marching forward, ensuring the high academic level and status of this journal. Therefore, these big changes are like a new journey and a new mission. Our hope is that General Psychiatry will reach the summit of this path we are on.

In future development, General Psychiatry will also strive to grasp new directions in the field of mental health research. With a discerning eye towards state-of-the-art developments, the journal will embody research articles related to important mental health issues including severe depressive disorders, the impact of disasters on mental health, bipolar disorder, severe schizophrenia, substance abuse, chronic psychosomatic comorbidity, and adolescent and senile mental disorders. Moreover, we will include more brain imaging, genetics and molecular network studies, and be involved with the research progress of high-risk psychotic syndrome and psychotherapy, as well as interventions for disasters and suicide. $^{34}$
We will start using the ScholarOne submission system, and only English papers will be accepted, which will be more professional and effective. We sincerely invite researchers from around the world to submit their latest mental health findings, especially those that are of multidiscipline and are results of multinational teamwork, to General Psychiatry. In this brand new phase of development, let us work hand in hand, enabling General Psychiatry to play the role of the communication channel in mental health research among different countries.

The change of name and collaboration with the BMJ are both for meeting the requirement of the international development of psychiatric research, and the aim is to promote our former platform, to gain a broader international view and to achieve a better development in the global market.

Funding The authors have not declared a specific grant for this research from any funding agency in the public, commercial or not-for-profit sectors.

Competing interests None declared.

Patient consent Not required.

Provenance and peer review Commissioned; internally peer reviewed.

Open access This is an Open Access article distributed in accordance with the Creative Commons Attribution Non Commercial (CC BY-NC 4.0) license, which permits others to distribute, remix, adapt, build upon this work non-commercially, and license their derivative works on different terms, provided the original work is properly cited and the use is non-commercial. See: http://creativecommons.org/ licenses/by-nc/4.0

\section{REFERENCES}

1 Zhang M. Globalization and mental health and policy in China. Shanghai Arch Psychiatry 2009;21:1-6.

2 Zhang M, Hongfen C, Wenli F. Thoughts on building a community mental health service system with Chinese Characteristics. Lin Chuang Xin Shen Ji Bing Za Zhi 2008;14:1-6.

3 Xie B. Strategic mental health planning and its practice in China: retrospect and prospect. Shanghai Arch Psychiatry 2017;29:115-9.

4 Dentang L, Haixin C, Kaida J. Research Progress in biological studies of schizophrenia in China in 2017. Shanghai Arch Psychiatry 2018;30:147-53.

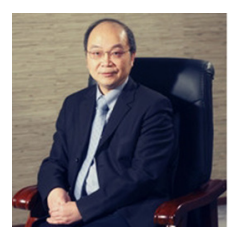

Shanghai Jiao Tong University School of Medicine, Shanghai, China. Dr. Yifeng Xu is Professor of Psychiatry and Chairman of the Department of Psychiatry at Shanghai Jiao Tong University School of Medicine (SJTUSM) in Shanghai, China. In addition, he is President of the Shanghai Mental Health Center (SMHC). In 1997, he was awarded a Freeman Fellowship to study medical anthropology at Harvard Medical School in Massachusetts, USA. Professor Xu maintains active basic and applied research programs, with interests centered on the clinical and environmental determinants of schizophrenia and depression. He has participated in multiple national and international research programs as a principal and co-principal investigator. Professor Xu has published more than 200 peer-reviewed journal articles and edited/translated a number of books, textbooks and monographs. His work has appeared in the Social Science E Medicine, Progress in Neuro-Psychopharmacology and Biological Psychiatry, BMC Medical Ethics, Journal of Affective Disorders, PLoS One, British Journal of Psychiatry, World Journal of Biological Psychiatry, Psychiatry Research, Nature Genetics, and Schizophrenia Research. Professor Xu is past Chairman of the Chinese Psychiatrist Association. 